\section{Investigation of the Antimicrobial Activity of Soy Peptides by Developing a High} Throughput Drug Screening Assay

\author{
Rekha Dhayakaran $^{1}$, Suresh Neethirajan ${ }^{1}$, Xuan Weng ${ }^{1}$ \\ ${ }^{1}$ Bionano Laboratory, School of Engineering, University of Guelph, Guelph, Canada N1G 2W1 \\ *Corresponding author Tel.: +1 5198244120 Ext: 53922; Email: sneethir@uoguelph.ca
}

\title{
Abstract
}

Background: Antimicrobial resistance is a great concern in the medical community, as well as food industry. Soy peptides were tested against bacterial biofilms for their antimicrobial activity. A high throughput drug screening assay was developed using microfluidic technology, RAMAN spectroscopy, and optical microscopy for rapid screening of antimicrobials and rapid identification of pathogens.

Methods: Synthesized PGTAVFK and IKAFKEATKVDKVVVLWTA soy peptides were tested against Pseudomonas aeruginosa and Listeria monocytogenes using a microdilution assay. Microfluidic technology in combination with Surface Enhanced RAMAN Spectroscopy (SERS) and optical microscopy was used for rapid screening of soy peptides, pathogen identification, and to visualize the impact of selected peptides.

Results: The PGTAVFK peptide did not significantly affect $P$. aeruginosa, although it had an inhibitory effect on L. monocytogenes above a concentration of $625 \mu \mathrm{M}$. IKAFKEATKVDKVVVLWTA was effective against both $P$. aeruginosa and L. monocytogenes above a concentration of $37.2 \mu \mathrm{M}$. High throughput drug screening assays were able to reduce the screening and bacterial detection time to $4 \mathrm{~h}$. SERS spectra was used to distinguish the two bacterial species. 
Conclusions: PGTAVFK and IKAFKEATKVDKVVVLWTA soy peptides showed antimicrobial activity against $P$. aeruginosa and L. monocytogenes. Development of high throughput assays could streamline the drug screening and bacterial detection process.

26 General significance: The results of this study show that the antimicrobial properties,

27 biocompatibility, and biodegradability of soy peptides could possibly make them an alternative

28 to the ineffective antimicrobials and antibiotics currently used in the food and medical fields.

29 High throughput drug screening assays could help hasten pre-clinical trials in the medical field.

Keywords: Antimicrobial peptides; microfluidics; biofilms; Surface Enhanced RAMAN

Spectroscopy

Antibiotic resistance is a significant challenge throughout the world today [43]. Extensive

or ineffective use of antibiotics and antimicrobials in both the medical and food industry has led

to increases in antibiotic resistance [43]. In nature, microorganisms do not always live in their

37 planktonic forms, rather, they are found in dynamic complex structures called biofilms [18, 46].

The adaptability of pathogenic bacterial biofilms to different physiological conditions and treatments enables them to emerge as resistant strains [13]. Therefore, there is a need to develop new antimicrobial agents and antibiotics that could effectively destroy pathogenic biofilms. Bioactive antimicrobial peptides (AMPs) are a new class of bio-pharmaceuticals released from proteins that exhibit unique antimicrobial, antioxidant, and antihypertensive properties [10, 19, 29, 36]. These are specific protein fragments encrypted in the amino acid sequences, which have

44 a positive impact on health and bodily functions [19, 20, 25]. By binding to specific receptors on target cells, they can regulate functional properties. For example, lactoferricin possesses 
47 caseniate possesses antioxidant, antihypertensive, and antimicrobial properties [4, 11, 40]. AMPs

48 have some common features, including short chain sequences (generally 12-50 amino acid

49 sequences), strong cationic characters (net charge ranging from +2 to +9 ), heat stability, and

50 amphipathic natures, while they can be derived from plants, animals, insects, and engineered

51 microorganisms, or could be synthesized [24, 35]. Although peptides are diverse in the amino

52 acid sequences that make up their structure, they can be classified into four main categories: (a)

$53 \alpha$-helices, (b) $\beta$-sheets, (c) extended helices, and (d) loop-forming structures [35]. Currently,

54 numerous efforts are focussed towards understanding the antimicrobial efficacy and mode of

55 action of AMPs on bacterial cells.

AMPs interact with bacterial cell membranes and penetrate cells changing the $\mathrm{pH}$

57 gradient, membrane potential, and osmotic regulation, thereby affecting respiration [24].

58 Influencing intra-cellular mechanisms, such as immuno-modulatory relationships, disrupting the

59 cell membrane and forming pores are other possible modes of action of AMPs [27]. Pore

60 formation is an important mechanism by which peptides cause cell death. Four models have been

61 used to explain this phenomenon: (i) the toroidal model where the peptides that attach to cell

62 membranes aggregate, and the lipid monolayers bend continuously acquiring positive curvature.

63 Through this pore, the peptides enter and destroy the cell's contents. In (ii) the carpet model,

64 AMPs cover the surface of the cell like a carpet until a threshold is reached to form membrane

65 patches in which the lipids aggregate. This weakens the bilayer and forms pores. Therefore,

66 membrane disruption occurs leading to lysis. In (iii) the barrel-stave model, bundles of peptides

67 oligomerize and form membrane pores on the microbe, thus enabling them to interact with the

68 hydrophobic core. Therefore microbes die either by membrane disruption, cell leakage, or loss of

69 polarization. In the final (iv) aggregate channel model, peptides penetrate bacterial cells and 
form clusters and aggregates. The water molecules then facilitate the leakage of ions from the

71 cell [24]. AMPs are also implicated in the inhibition of DNA, protein, and RNA synthesis,

72 interference with cytokinesis, alteration of cytoplasmic membrane formation, and the inhibition

73 of enzymatic activities [24].

Peptides usually occur as $\alpha$-helix or $\beta$-sheets or as a combination of both. There are two common characteristics shared by most AMPs, a net positive charge and amphipathic structure. These two factors help peptides bind the cell membrane, increasing permeability [26]. It is generally accepted that long chain peptides insert themselves into bacterial cells forming pores that lead to cell death. When the net positive charge of a peptide is high, it has the ability to interact effectively with the negatively charged bacterial outer membrane [24]. The length and composition of amino acid sequences affect the formation of aggregates and dissociation during the interaction [26]. Therefore, peptides may hold promise as antimicrobial agents, although screening methodologies for testing new antimicrobials are lacking. agents and antibiotics. These protocols are of use in the fields of food safety, pharmacology,

85 environmental, and water quality monitoring, although there are some disadvantages, such as 86 time consumption, intensive labor, the requirement of large amounts of sample or reagents, and

87 the exposure to contamination [22, 41]. In addition, conventional assays cannot be used for intermediate testing, such as examining the kinetics of microbes, exploring topography, or

89 characterizing the biochemical spectra. The other major issue with conventional assays is that the 90 actual environment of microbial growth cannot be mimicked in flasks, test tubes, or microtitre

91 wells [22]. Microfluidics technology is a fast-growing field that overcomes the disadvantages of 92 these conventional assays by being able to provide high throughput screening, real-time 
93 examination of samples, usage of very low amounts of reagents, rapid screening, parallel testing

94 of multiple drugs, all while saving space [9, 21, 33, 42, 44, 45, 48]. High throughput screening

95 (HTS) platforms have improved drug delivery processes and are playing a vital role in the

96 discovery of anti-cancer drugs and the characterization of drug metabolism and cytotoxicity [1,

$9723,37,49]$.

In this study, the antimicrobial efficacy of soy based antimicrobial peptides (PGTAVFK

and IKAFKEATKVDKVVVLWTA) against Listeria monocytogenes and Pseudomonas

100

101

102

103

104

105

106

107

108

109

110

111

2. Materials and Methods

\subsection{Bacterial Strains}

P. aeruginosa strain PA-76, isolated from canine ear skin infections was obtained as a gift from the Ontario Veterinary College (OVC), Guelph, Canada. L. monocytogenes strain C379, an isolate from chicken wieners was obtained as a gift from the Canadian Research Institute for Food Safety (CRIFS), University of Guelph, Canada.

\subsection{Culture conditions}

P. aeruginosa and L. monocytogenes were obtained as frozen stocks $\left(-80^{\circ} \mathrm{C}\right)$. From this, the bacterial strains were streaked onto $5 \%$ sheep blood agar plates (SBP) and incubated at $37^{\circ} \mathrm{C}$ for $24 \mathrm{~h}$. For subsequent experiments, colonies from these plates were used for culturing bacteria 
in Mueller Hinton-II broth (MHB) for P. aeruginosa, and brain heart infusion broth (BHI) for $L$. monocytogenes.

\subsection{Peptide Synthesis}

Synthesized soy peptides PGTAVFK and IKAFKEATKVDKVVVLWTA were purchased from Genemed Synthesis Inc., (Texas, USA). The molecular weight of the first short chain peptide PGTAVFK was $718.4 \mathrm{~g} / \mathrm{mol}$, and the other long chain peptide IKAFKEATKVDKVVVLWTA was $2146.4 \mathrm{~g} / \mathrm{mol}$. They were synthesized by 9fluorenylmethoxicarbonyl (fmoc) solid-phase synthesis and purified to $98.62 \%$ and $97.59 \%$, respectively using a C-18 high performance liquid chromatography (HPLC) reverse column [14]. Upon receiving the peptides, they were stored at $4^{\circ} \mathrm{C}$. A $7 \mathrm{mg}$ amount of PGTAVFK peptide was dissolved in $1 \mathrm{ml}$ of sterile phosphate buffered saline (PBS; $\mathrm{pH}=7.0$ ) and stored at $-25^{\circ} \mathrm{C}$ until further use. A $10 \mathrm{mg}$ of IKAFKEATKVDKVVVLWTA peptide was dissolved in $1 \mathrm{ml}$ of sterile PBS and stored at $-25^{\circ} \mathrm{C}$ until further use. The stock concentrations were therefore $5 \mathrm{mM}$ for PGTAVFK and $4.66 \mathrm{mM}$ for of IKAFKEATKVDKVVVLWTA.

\subsection{Antimicrobial Assay}

The microdilution assay was adapted from Motyl et al [30]. P. aeruginosa was grown in $6 \mathrm{ml}$ cation adjusted Mueller Hinton broth (Sigma Aldrich, Canada), and L. monocytogenes was grown in $6 \mathrm{ml}$ Brain Heart Infusion Broth (Thermo Scientific, Canada). Mueller Hinton broth is the commonly used media for performing susceptibility tests for fast growing clinically isolated bacteria. While performing preliminary experiments, it was found that $L$. monocytogenes did not grow in Mueller Hinton broth. BHI is rich in nutrients and is suitable for fastidious organisms like L. monocytogenes. Both bacteria were grown at $37^{\circ} \mathrm{C}$ in the respective broth until the cell density was above the $0.5 \mathrm{McFarland}$ barium sulfate standard, while the cells are in the 
logarithmic growth phase. This inoculum was then diluted 1:140 times in the respective media. $100 \mu \mathrm{l}$ of media was added to each well tested in a 96-wells microtitre plate. Then, $200 \mu 1$ of 5 mM PGTAVFK and $2.3 \mathrm{mM}$ IKAFKEATKVDKVVVLWTA soy peptide solutions were added to the first well (column 1), and each row was serially diluted two-fold to column 11 of the 96well microtitre plate. Column 12 was reserved for the control and did not contain any peptide solution. Tests were separately carried out with the two peptides. Lactoferricin was used as positive control, as it is a better-characterized peptide that has been shown to have antimicrobial activity against $L$. monocytogenes and $P$. aeruginosa $[32,34]$. Concentrations of lactoferricin ranging from $8 \mu \mathrm{g} / \mathrm{ml}$ to $0.1 \mathrm{mg} / \mathrm{ml}$ have been shown to be effective against these organisms; our results were consistent with these observations (data not shown). Using a pipette, $100 \mu$ of the diluted inoculum was added to all wells in the plate. A final inoculum of $4-8 \times 10^{5} \mathrm{CFU} / \mathrm{ml}$ was achieved for each bacterial species. The final soy peptide concentrations ranged from $2.5 \mathrm{mM}$ in column 1 to $2.44 \mu \mathrm{M}$ in column 11 . Plates were then covered and incubated at $37^{\circ} \mathrm{C}$. At $24 \mathrm{~h}$, the plates were taken out, and the optical density was read using a Biotrak II plate reader (Amersham Biosciences, Canada). All assays were performed in triplicate.

\subsection{Microfluidic Platform}

The microfluidic device was designed using AutoCAD 2015 (Autodesk Inc, USA). The vision behind designing this device was to fabricate a 3D high throughput drug screening device consisting of a glass bottom layer, a polydimethylsiloxane (PDMS) second layer with a bacterial dispenser, loading channels, and 24 incubation chambers, and a final top PDMS layer with 4 concentration generating gradients and connective channels. The glass base was $70 \mathrm{~mm} \mathrm{X} 70$ $\mathrm{mm}$; the central reservoir for dispensing bacteria was designed to have a diameter of $2.5 \mathrm{~mm}$. The 24 incubating chambers were $2 \mathrm{~mm}$ in diameter, and the loading channels were $12.75 \mathrm{~mm}$ 
162 long and $60 \mu \mathrm{m}$ wide. The 4 concentration gradient generators (width $=100 \mu \mathrm{m}$ ) consisted of 8 163 inlets (each was $0.75 \mathrm{~mm}$ in diameter) to flow different concentrations of soy peptide with PBS

164 buffer. The gradient generators were uniformly designed to ensure that they use laminar flow and 165 diffusive mixing to form a steady mixture of PBS and peptide solution. The inlets were only 166 present on the top layer to allow for proper mixing and the flow of peptide solution. The 167 connecting channels were about $10-15 \mathrm{~mm}$ in length, while the width was varied from 100 to 30 $168 \mu \mathrm{m}$ to avoid the backflow of bacteria into these channels. Once the device was designed, the 169 mask was custom made from Fine Line Imaging (Colorado, USA). From the mask, master 170 moulds were fabricated using photo-lithographic technique. The design of this 3D high 171 throughput microfluidic platform is shown in Figure 1.

172 A total of $35 \mathrm{~g}$ of PDMS elastomer base was mixed with $3.5 \mathrm{~g}$ of curing agent (Dow 173 Corning Sylgard 184, USA). It was then poured out on the silicon wafer individually. The wafers 174 were then desiccated and baked at $60^{\circ} \mathrm{C}$ for the PDMS mould to harden. The device was then 175 removed from the wafer, cut, and holes were punched (Harris Uni-Core, Sigma Chemical Co., 176 USA). The inlet holes on the top layer were $0.75 \mathrm{~mm}$ in diameter, the bacterial dispensing 177 chamber was $0.75 \mathrm{~mm}$ in diameter, and the 24 incubating chambers were $2 \mathrm{~mm}$ in diameter. 178 Both the layers along with the glass base were plasma cleaned (Harrick Plasma, Ithaca, USA) to 179 remove debris and to enhance the bonding between various layers. Then, the layers were assembled and baked at $60^{\circ} \mathrm{C}$ for 30 minutes to strengthen the bond. 
bioRxiv preprint doi: https://doi.org/10.1101/045294; this version posted March 23, 2016. The copyright holder for this preprint (which was not certified by peer review) is the author/funder, who has granted bioRxiv a license to display the preprint in perpetuity. It is made available under aCC-BY-NC-ND 4.0 International license.

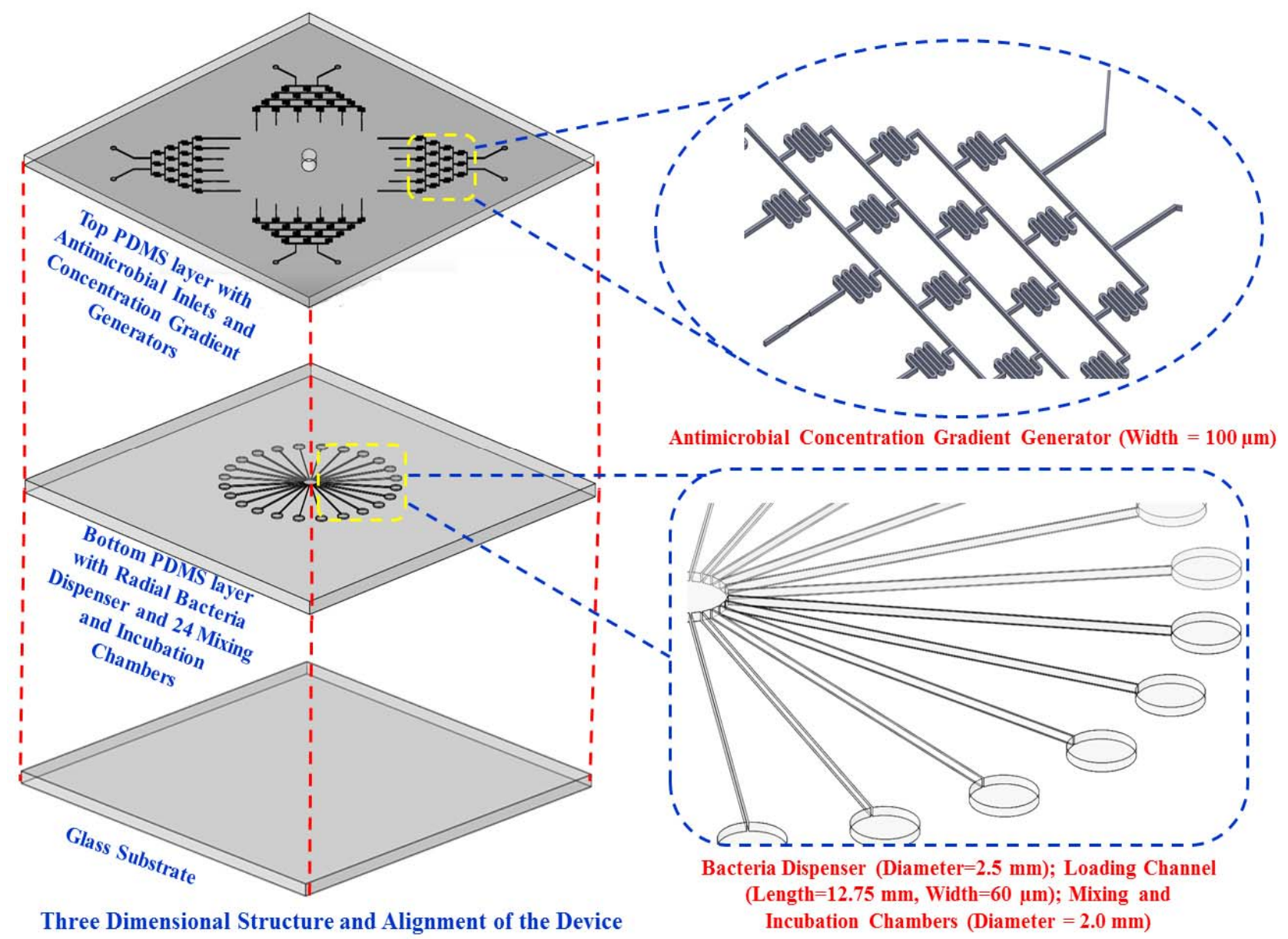




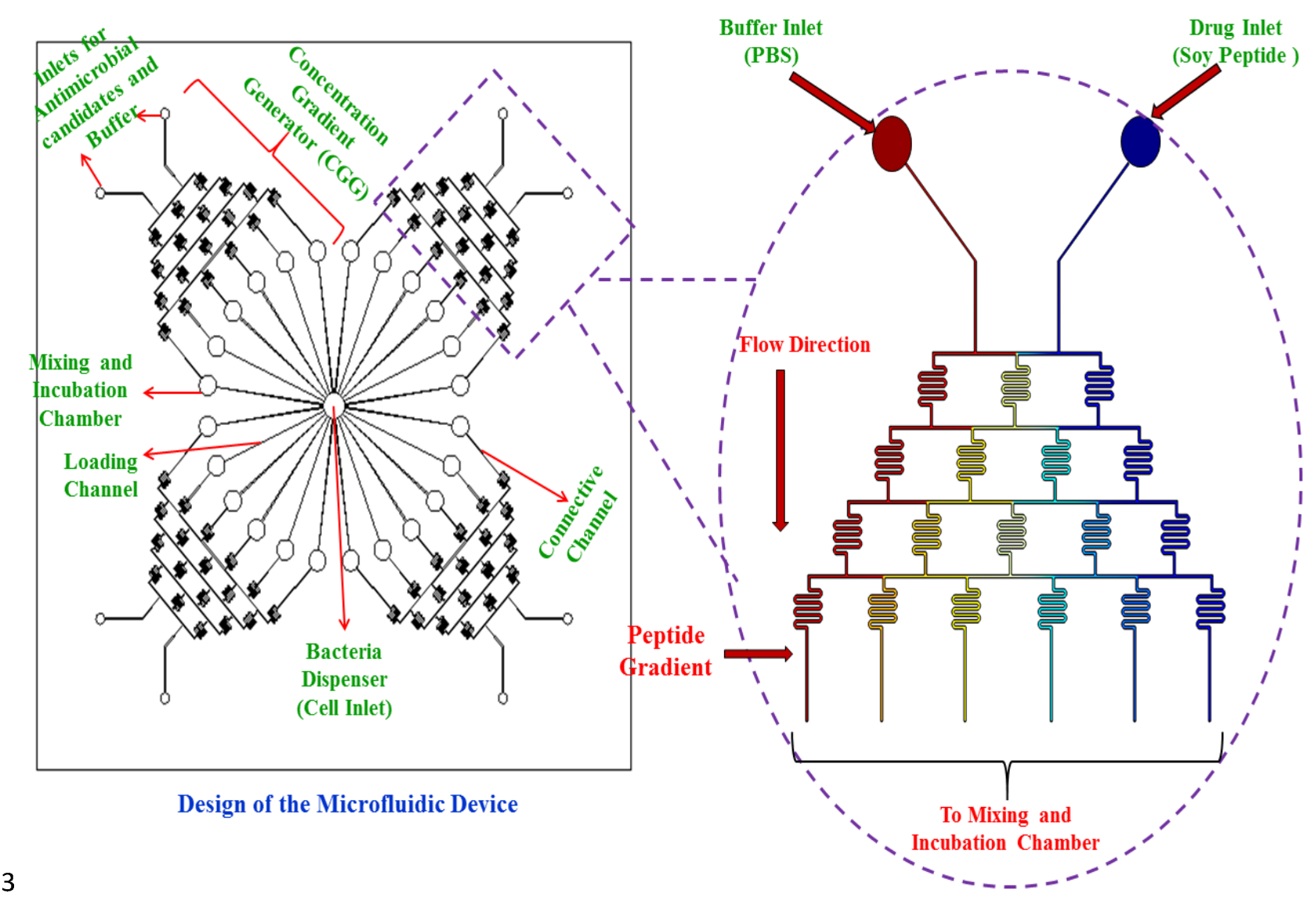

Figure 1. Design of the 3D microfluidic high-throughput drug screening platform: (i) three layers of the microfluidic device and a magnified view of the serpentine-like channels in the

The top view of the microfluidic platform and a magnified view of the complete CGG with gradient generated by the soy peptide and buffer solution at the end of the generator.

\subsection{Characterization of the Microfluidic Device}


195

196

197

198

199

200

201

202

203

204

205

206

207

208

209

210

211

212

213

214

215

216

prepared in water. A $5 \mu \mathrm{M}$ solution was prepared from this stock and injected in one of the inlets of a CGG along with water at the other inlet of CGG. Syringe pumps were used for controlled injection $(20 \mu \mathrm{l} / \mathrm{h})$ of water and fluorescein dye into the CGG (Chemyx Fusion Touch, USA) through a $1 \mathrm{~mm}$ syringe and $0.3 \mathrm{~mm}$ needle tips (Becton, Dickinson and Company, USA). Images were taken using an inverted Nikon Eclipse Ti microscope with a green filter. Images were processed using ImageJ software (NIH, USA).

\subsection{Cell Seeding into the Microfluidic Device}

P. aeruginosa and L. monocytogenes treated with IKAFKEATKVDKVVVLWTA (long chain) peptide were used for all microfluidic experiments. The cell suspensions were prepared from overnight cultures grown at $37^{\circ} \mathrm{C}$ in their respective broth solutions. One $\mathrm{ml}$ of this culture was centrifuged (SciLogex D3024, USA) at $3000 \mathrm{rpm}$ for 3 minutes. The supernatant was removed, and the pellet was suspended in sterile PBS. This was then diluted to a $0.5 \mathrm{McFarland}$ Standard and used for further experimentation to ensure that cells would be poised to grow once inoculated. The cells were injected into the bacterial dispensing chamber at the center of the device. Once the loading channels and 24 chambers started to fill with bacteria, soy peptide at a concentration of $4.6 \mu \mathrm{M}, 37.2 \mu \mathrm{M}, 74.4 \mu \mathrm{M}$, and $298 \mu \mathrm{M}$ was injected into the inlets of 4 CGGs, along with PBS buffer, using $1 \mathrm{~mm}$ syringes with $0.3 \mathrm{~mm}$ needle tips (Becton, Dickinson and Company, USA). The flow rate $(20 \mu \mathrm{l} / \mathrm{h})$ was controlled using syringe pumps (Chemyx Fusion Touch 200 and 400, USA; Harvard Apparatus Pump 11 Elite, USA). The temperature of the device was maintained at $37^{\circ} \mathrm{C}$ using a temperature controller stage. Once the concentration gradients start to fill and the 24 wells were filled with the peptide and bacterial mixture, the syringe pumps were turned off and the bacteria were incubated in the device. 


\subsection{RAMAN Spectroscopy Analysis}

RAMAN Spectroscopy was used in identifying $P$. aeruginosa and L. monocytogenes before and after various treatments with long chain peptides. This was done to emphasize that the spectral signature of the bacteria and peptide mixture at different dosage levels could be used to validate the high throughput drug screening microfluidic device and show the efficacy of peptides against bacteria. $P$. aeruginosa and $L$. monocytogenes were incubated at a $1: 1(\mathrm{v} / \mathrm{v})$ ratio of long chain peptide (IKAFKEATKVDKVVVLWTA) for $4 \mathrm{~h}$ at $37 \square \mathrm{C}$ to obtain final peptide concentrations of $4.6 \mu \mathrm{M}, 37.2 \mu \mathrm{M}, 74.4 \mu \mathrm{M}, 100 \mu \mathrm{M}$, and $298 \mu \mathrm{M}$. RAMAN spectra was obtained using a $785 \mathrm{~nm}$ RAMAN spectrometer (Snowy Range Instruments, WY, USA) for control and all treatments on a surface enhanced (SERS) gold substrate $(5 \mathrm{~mm} \mathrm{X} 5 \mathrm{~mm}$; Nanova Inc, USA). Spectra obtained on glass substrates (without SERS substrate) did not show any visually significant peaks or differences compared to the peptide treated bacterial samples (data not shown). Ampicillin was used as a control in this experiment.

\subsection{Time Lapsed Microscopy Analysis}

A 0.5 McFarland standard of L. monocytogenes (in logarithmic growth phase) was mixed with the long chain soy peptide to obtain final concentrations of $37.2 \mu \mathrm{M}$ and $200 \mu \mathrm{M}$ of soy peptide in microfuge tubes. A $10 \mu \mathrm{l}$ of this mixture was added to the well in a microfluidic device and immediately placed under a Nikon Eclipse $\mathrm{Ti}$ inverted microscope (Nikon Instruments Inc., Melville, NY). A total $10 \mu 1$ of the solution ensured that the individual bacterial cells were exposed to sufficient volumes of media. Images were captured focusing on the same region of interest over a $3 \mathrm{~h}$ time period with a 40x objective lens in the phase contrast 1 mode, equipped with the NCB and D filters. This experiment was performed to visualize the 
antimicrobial effect of the long chain soy peptide on bacterial cells. All experiments were performed in triplicate and analyzed using IBM SPSS Statistics 22.

\section{Results and Discussion}

\subsection{Choice of Peptides for this Study}

After a detailed literature review, we determined that the therapeutic potential and antimicrobial properties of soy based peptides have not been widely studied. Therefore, two peptides of soy origin (PGTAVFK and IKAFKEATKVDKVVVLWTA) were chosen for this study based on three published papers that investigated: 1) the antimicrobial activity of PGTAVFK against Escherichia coli and Staphylococcus aureus, 2) the activity of fragment (213-231) of the enzyme D-myo-inositol-3-phosphate synthase from soybean (GenBank accession number: ABM17058.1) against Asian rust spores, and 3) the activity of myoinositol as a termicide $[3,28,39]$.

Bacterial protein phosphorylation has been recently identified as a promising target for the development of new antibacterial compounds [5]. D-myo-inositol 3-phosphate synthase is an enzyme that has the ability to catalyze the production of phospholipids during salvage. Inositol is a metabolic sensor for numerous signal transduction pathways that specifically has the ability to disrupt cellular processes during the unfolded protein response [17]. The sequence of fragment (213-231) from D-myo-inositol-3-phosphate synthase is IKAFKEATKVDKVVVLWTA [3].[3]. Therefore PGTAVFK and IKAFKEATKVDKVVVLWTA were chosen as antimicrobial peptide candidates for this study. 


\subsection{Antimicrobial Testing Using Microdilution Assay}

261

Microdilution assays were performed to examine the antimicrobial efficacy of both short

262 chain (PGTAVFK) and long chain (IKAFKEATKVDKVVVLWTA) soy peptides against $P$.

263 aeruginosa and L. monocytogenes. Figure 2 (PGTAVFK) and Figure 3

264 (IKAFKEATKVDKVVVLWTA) show the effects of these two soy peptides on the optical

265 density of bacterial cultures, which reflects their antimicrobial capacities (ability to stop/slow

266 growth). PGTAVFK did not significantly affect $P$. aeruginosa culture density, but it had an

267 inhibitory effect on L. monocytogenes at a concentration above $625 \mu \mathrm{M}$.

268 IKAFKEATKVDKVVVLWTA, on the other hand, was effective against both $P$. aeruginosa and

269 L. monocytogenes at concentrations above $37.2 \mu \mathrm{M}$. It is apparent from our results that both

270 antimicrobial peptides can affect the optical density of the organisms, which represents the

271 concentration of the suspended organisms and the sum total of growth and cell death. Therefore,

272 we cannot speculate whether the major modes of actions for these peptides are bactericidal

273 versus bacteriostatic; future studies will explore the precise mechanisms of action. 


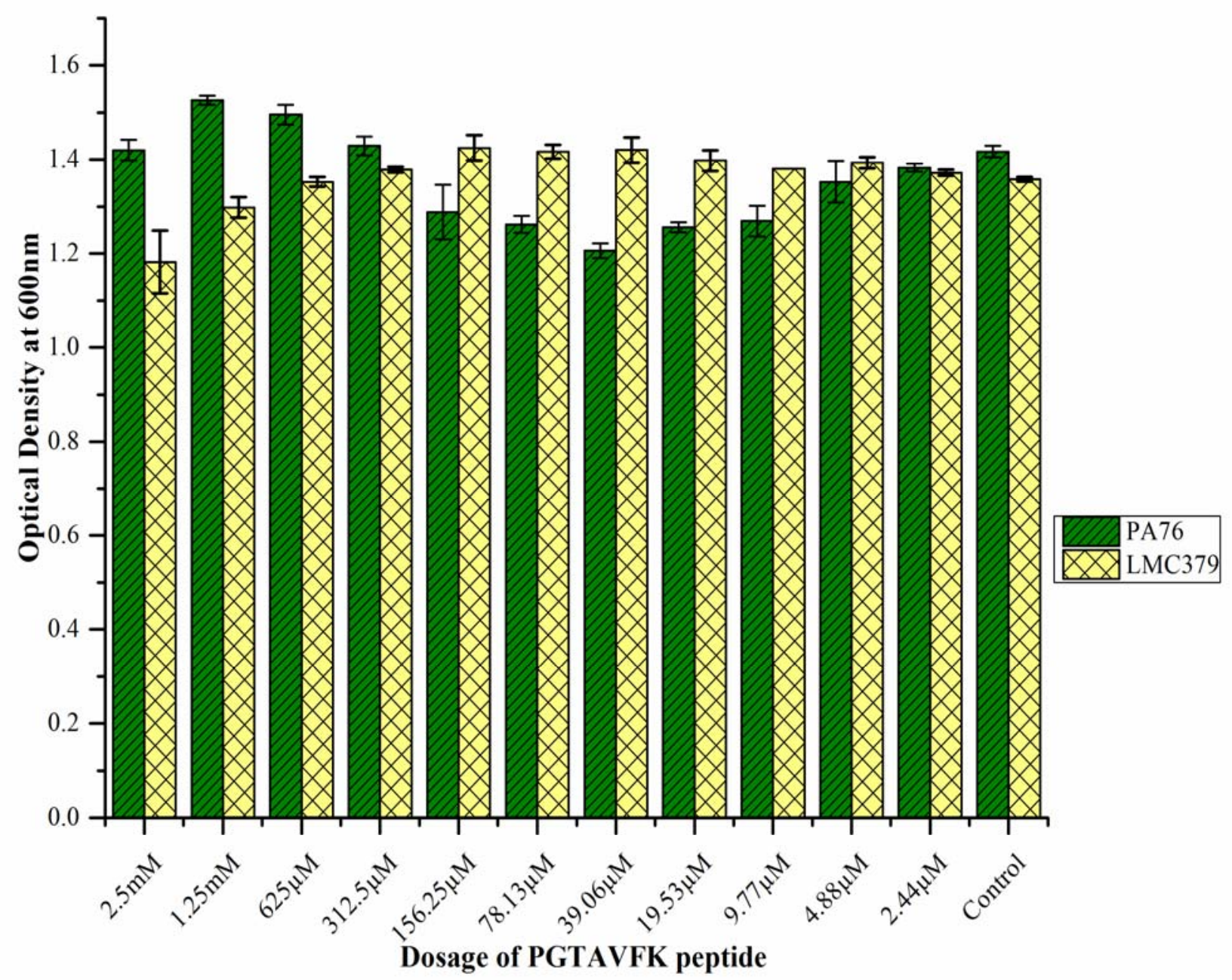

275 Figure 2. Antimicrobial activity of the soy peptide PGTAVFK against P. aeruginosa PA76 and

276 L. monocytogenes C379. The soy peptide did not inhibit the bacterial growth of P. aeruginosa

277 significantly but had an inhibitory effect on L. monocytogenes at concentrations above $625 \mu \mathrm{M}$. 


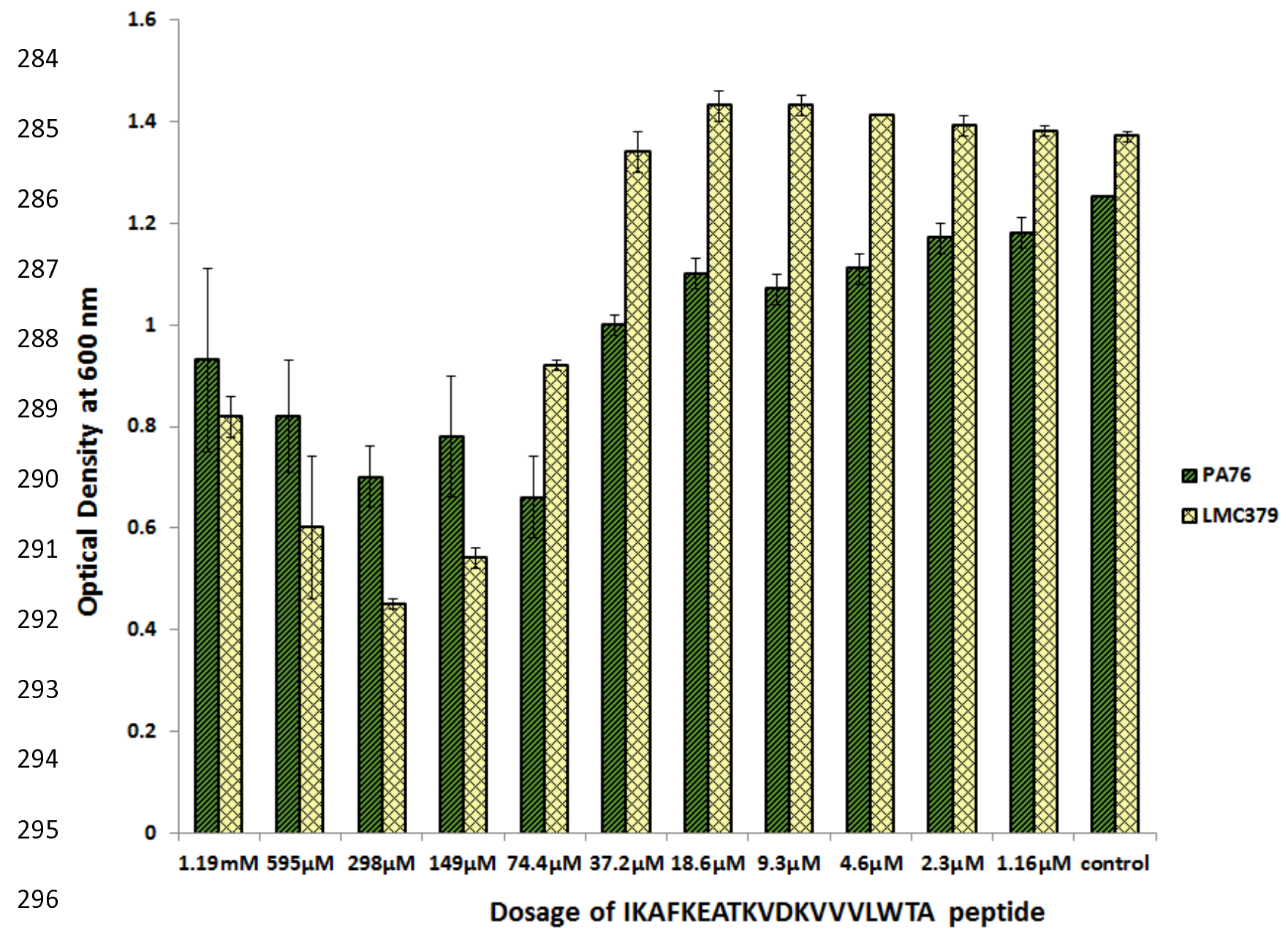

297 Figure 3. Antimicrobial activity of the soy peptide IKAFKEATKVDKVVVLWTA against $P$.

298 aeruginosa and L. monocytogenes. The soy peptide inhibited both strains of bacteria at a 299 concentration as low as $37.2 \mu \mathrm{M}$.

300

The difference in antimicrobial efficacy between the short and long chain peptides could

302 be attributed to the structure and length of the sequences ( 7 amino acid sequence: PGTAVFK; 19

303 amino acid sequence: IKAFKEATKVDKVVVLWTA). As discussed previously, long chain

304 peptides are generally associated with high antibacterial activity. The difference in the net

305 positive charges of the two peptides could also have contributed to differences in their

306 antibacterial activity. The activity of AMPs could be affected by the concentrations of cations 
and anions present in their environment [12]. Therefore, the combination of amino acids in the sequences of peptides could have affected their antibacterial efficacy.

It has been demonstrated that some cations neutralize repulsive forces of adjacent lipopolysaccharide (LPS) in the outer membrane of Gram-negative bacteria, leading to a tight and cross-linked outer membrane that protects itself from hydrophobic surfaces and AMPs [26]. LPS moieties differ in composition and length among bacterial species, which could possibly be a reason why the long chain peptide was able to act effectively on $P$. aeruginosa, while the short chain peptide was largely inactive [26]. This could also be the reason why PGTAVFK was not able to significantly inhibit $P$. aeruginosa but was able to inhibit L. monocytogenes, a Grampositive bacterium. Once AMPs pass through the LPS in outer membrane, there is an inner membrane comprised of phospholipids on both sides of the bilayer. Therefore, a peptide that could enter the outer membrane need not necessarily interact efficiently with the inner membrane. It has been reported that peptides form aggregates in solution, which makes it difficult for them to enter the outer membrane and reach the target, which is the cytoplasmic membrane [26]. However, no aggregates were visually observed in either prepared peptide solution used in our experiments. LPS forms aggregates in solution that are biologically active and toxic. Therefore, dissociation of these aggregates is required to neutralize and inactivate LPS. These could be some plausible reasons for the observed differential sensitivity.

\subsection{Characterization of our High Throughput 3D Microfluidic Platform}

Characterization of the 3D microfluidic device was performed to show that this device could be used for multiplexing, parallel concentration gradient generation, and drug screening applying various concentrations simultaneously. Moreover, the use of PDMS helps in creating an 
329 inexpensive, biocompatible, and transparent environment that allows the use of this device in

330 further quantification through optical and RAMAN imaging.

Under continuous flow conditions, the 3D high throughput device was characterized

332 using $5 \mu \mathrm{M}$ fluorescein dye. Figure 4 shows the concentration gradient formed in the six

333 channels in terms of fluorescence intensity. Diffusion of fluorescein into the PDMS layer forms

334 concentration gradients. Images of fluorescence in all six channels were obtained using Nikon Ti

335 inverted microscope, and the intensity of fluorescence was then measured from 6 channels and

336 normalized. We found that the fluorescence intensity increases with increasing channel number.

337 Formation of air bubbles in the serpentine-like pathways of the microfluidic platform may block

338 fluid flow causing non-linearity, which can be avoided by prober bonding of the PDMS with the

339 glass slide and an accurate device design chip. It is quite important that the thickness of PDMS

340 layers is uniform for a proper concentration gradient generation. Our group and others have

341 successfully demonstrated that it is possible to generate a linear concentration of drug molecules

342 using a microfluidic device of similar design; results from this study are consistent with these

343 previous studies $[7,16]$. 


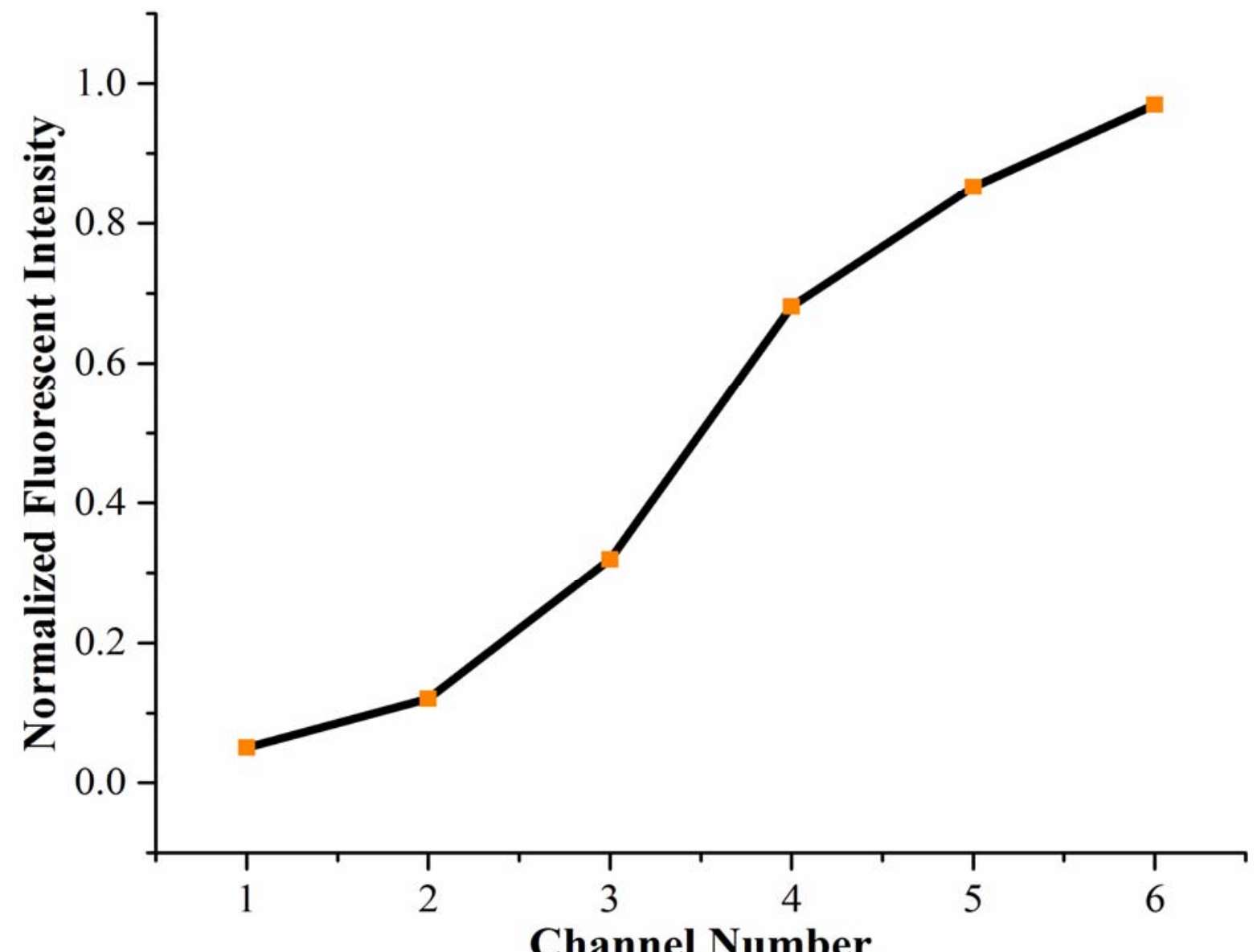

Figure 4. Characterization of the 3D microfluidic high throughput drug screening device with 5 $\mu \mathrm{M}$ of fluorescein and buffer at the inlets of device at a flow rate of $20 \mu 1 \mathrm{~h}^{-1}$. The relationship between the normalized fluorescent intensity and the channel number shows that intensity

348 increases with increasing channel number implying that the concentration gradient generator of the device (CGG) produces linear concentrations of fluorescein in the device.

\subsection{RAMAN Spectra Analysis}

353 point-of-care diagnostics applications [2, 31]. Here, it was used in conjunction with the 3D microfluidic platform to validate that by reducing the sample volume to few microliters in a 
355 microfluidic device, the incubation time for detection could be reduced drastically to identify

356 bacterial species. Owing to the microliter volume size of the peptide solutions in each well of the

357 microfluidic incubation chamber and the enhanced surface to volume ratio, there is a rapid

358 kinetic reaction between the peptide and the individual bacterial cells, leading to a decreased

359 incubation time in comparison with the milliliter volumes of the conventional assays. We

360 recorded the SERS spectra at an excitation wavelength of $785 \mathrm{~nm}$ under various dosage levels of

361 long chain peptide (IKAFKEATKVDKVVVLWTA), treating both $P$. aeruginosa and $L$.

362 monocytogenes for $4 \mathrm{~h}$ at $37^{\circ} \mathrm{C}$ (Figure 5). We found that for the $P$. aeruginosa control, the

363 RAMAN peaks were visible at about 823,1270,1362, 1490, and $1510 \mathrm{~cm}^{-1}$ (highlighted and

364 circled in Figure 5 (i)). For the L. monocytogenes control, peaks were visible at about 716, 821,

3651022,1423 , and $1454 \mathrm{~cm}^{-1}$ (boxed and circled in Figure 5 (ii)). In both cases, these significant

366 peaks could not be observed in spectral curves of the treated samples, which suggest that the

367 peptides possess antimicrobial activity.

In an attempt to identify spectra of biomolecules found in microorganisms using an

excitation wavelength of $785 \mathrm{~nm}$, DNA and RNA bases were observed to dominate the region

370 between 600 and $800 \mathrm{~cm}^{-1}$; proteins in the form of amide I and III ranged from 1300 to $1655 \mathrm{~cm}^{-}$

$371{ }^{1}$, fatty acids fell in the range of $1300-1440 \mathrm{~cm}^{-1}$, and saccharides were between 1000 and 1200

$372 \mathrm{~cm}^{-1}$ and1300 and $1500 \mathrm{~cm}^{-1}$ [6]. The speculated molecular characterization of spectral peaks

373 observed in this study, with reference to the work of De Gelder et al [6], is shown in Table 1.

374 The spectral peaks observed for $P$. aeruginosa could be attributed to the presence of various

375 forms of fatty acids and DNA and RNA bases, while in L. monocytogenes, the peaks could be

376 attributed to the presence of fatty acids, saccharides, and amino acids. 
bioRxiv preprint doi: https://doi.org/10.1101/045294; this version posted March 23 2016. The copyright holder for this preprint (which was not certified by peer review) is the author/funder, who has granted bioRxiv a license to display the preprint in perpetuity. It is made available under aCC-BY-NC-ND 4.0 International license.

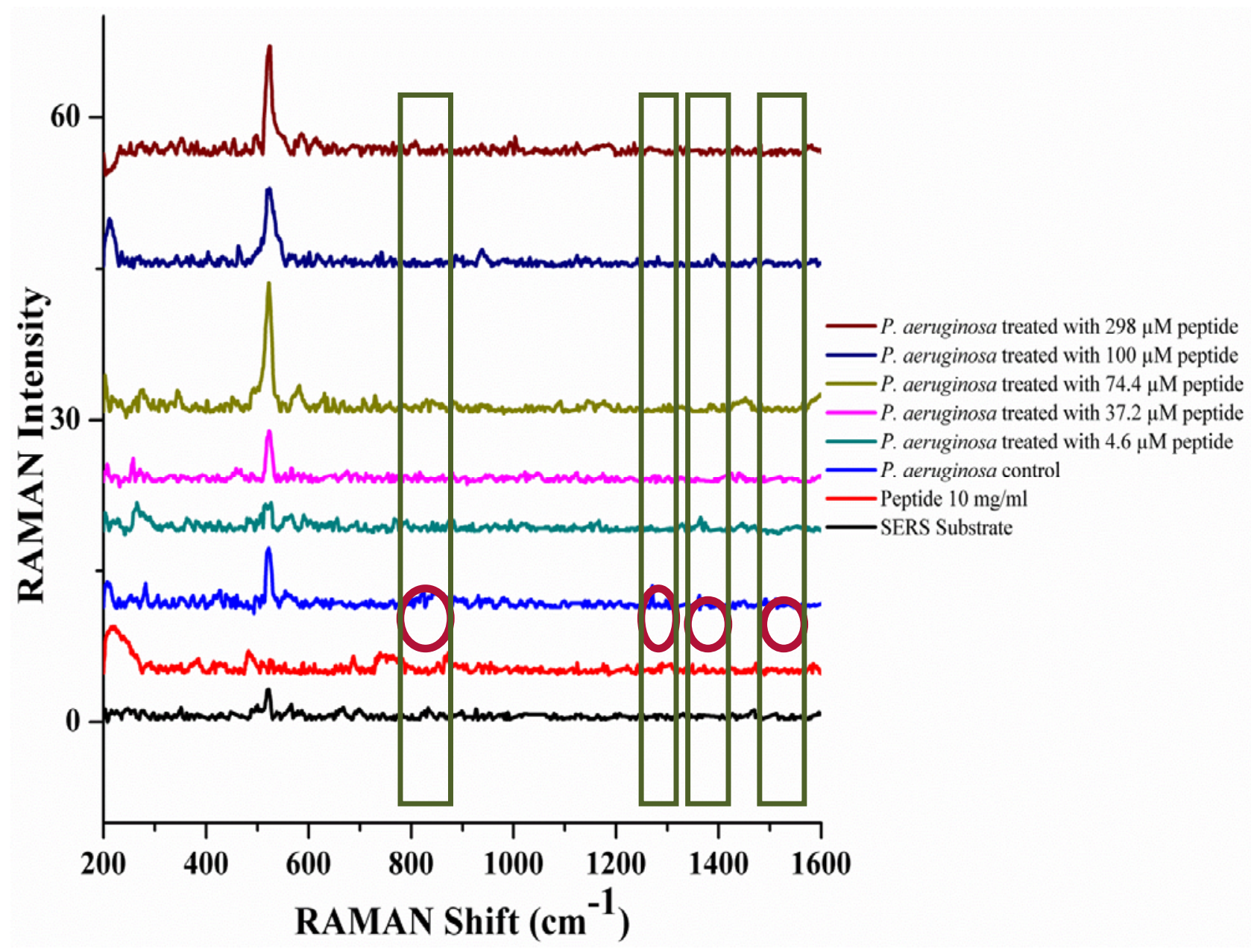




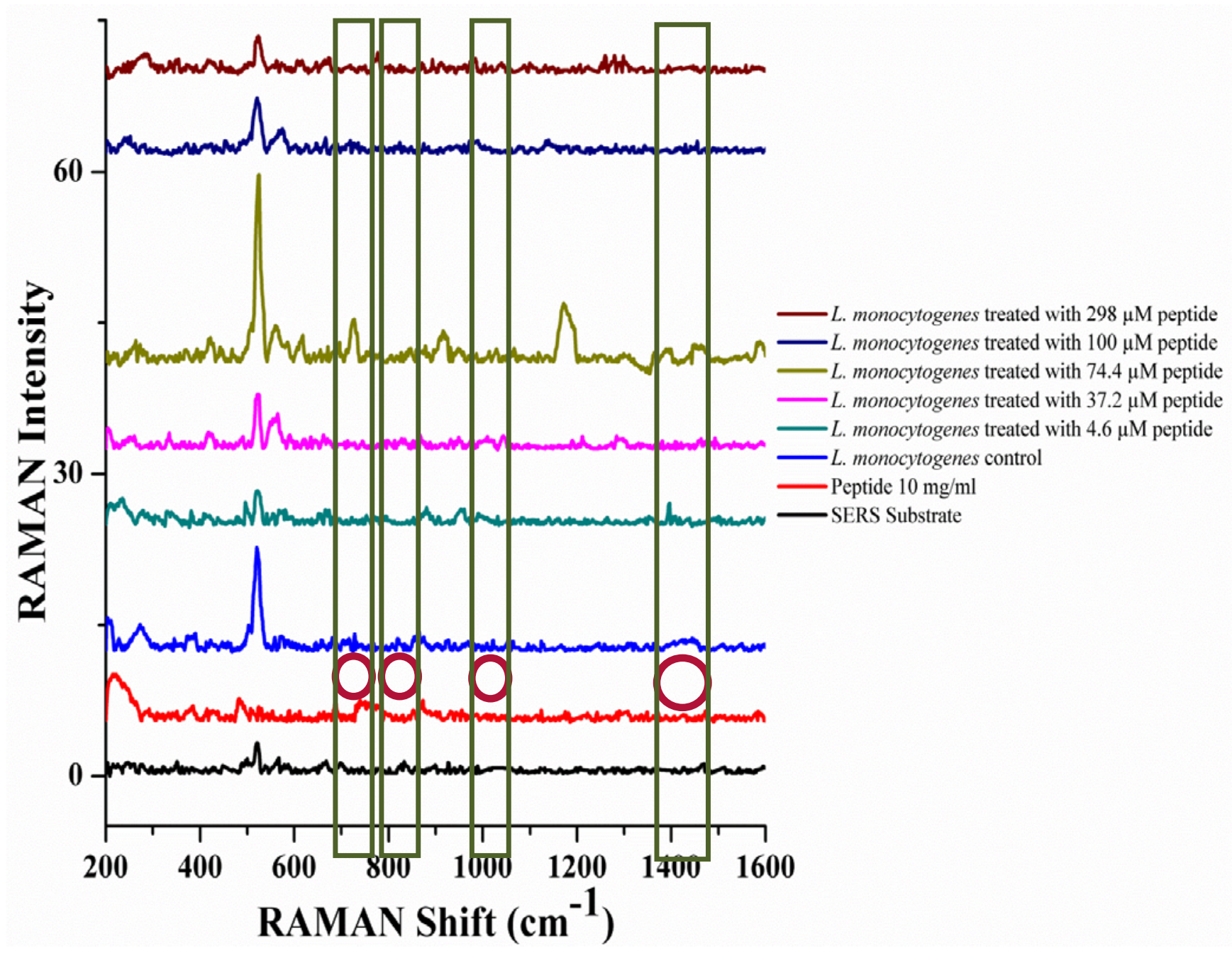

Figure 5. Surface Enhanced RAMAN Spectra (SERS) obtained for (i) P. aeruginosa and (ii) treatments are boxed. 
Table 1. Speculative assignment of peaks from the SERS spectra of $P$. aeruginosa and $L$. monocytogenes using a $785 \mathrm{~nm}$ excitation wavelength based on the characterization reported by De Gelder et al [6].

\begin{tabular}{lll}
\hline P. aeruginosa & L. monocytogenes & Assignment of RAMAN shift \\
\hline & $716 \mathrm{~cm}^{-1}$ & D-fructose 6 phosphate- saccharide \\
$823 \mathrm{~cm}^{-1}$ & $821 \mathrm{~cm}^{-1}$ & $\begin{array}{l}15 \text { - methylpalmatic acid (17iso)- phospholipid derived } \\
\text { fatty acid }\end{array}$ \\
& & $\alpha, \beta$ - D-glucose- saccharide \\
& $1022 \mathrm{~cm}^{-1}$ & 14 -methylpentadeconoic acid (16iso)- fatty acid \\
$1270 \mathrm{~cm}^{-1}$ & & Cytosine- DNA and RNA base \\
$1362 \mathrm{~cm}^{-1}$ & & L- tryptophan; L- proline- amino acids \\
& $1423-1454 \mathrm{~cm}^{-1}$ & Thymine- DNA base \\
$1490 \mathrm{~cm}^{-1}$ & & 12 -methyltetradeconoic acid (15Aiso)- fatty acid \\
$1510 \mathrm{~cm}^{-1}$ & &
\end{tabular}
even single molecule) and the possibility of using it in aqueous conditions with little or no interference [8]. The SERS substrate enhances the RAMAN intensity of samples due to the 400 surface roughness caused by the presence of metal nanoparticles (gold). Molecules in the 401 samples are adsorbed onto these surfaces, which increases the strength of detection. 
shown), which could be attributed to low sensitivity of the method. By using a SERS substrate, the spectral intensity improved, but the RAMAN shifts were still weak. It was speculated that the

406 incubation time and bacterial cell density have a direct correlation. If the bacterial cell density is

407 less, the incubation time could also be reduced and so forth. In these experiments, a 0.5

408 McFarland standard cell density was used (OD at $600 \mathrm{~nm}$ was between 0.08 and 0.1 ). Therefore 409 the amount of incubation time required to elicit visible strong changes in biochemical signatures 410 at this cell density could be longer than $4 \mathrm{~h}$.

Sockalingum et al [38] used different ways of mixing metal colloids with bacteria and observed SERS spectra using $632 \mathrm{~nm}$ excitation. It was found that the spectra of $E$. coli differed from that of $P$. aeruginosa by observing peaks of constituents, such as fatty acids, amino acids,

414 proteins, and nucleic acids. Using a $784 \mathrm{~nm}$ excitation, Guzelian et al [15] claimed that there 415 were different spectra for P. aeruginosa, L. monocytogenes, Bacillus subtilis, and Bacillus cereus 416 when placing bacteria on electrochemically roughened gold SERS strips. At 514, 633, and 780 $417 \mathrm{~nm}$, Efrima \& Zeiri [8] have also used the SERS technique to identify molecular information for 418 bacteria. Therefore, reproducibility and selectivity remain a drawback. However, when 419 controlling experimental conditions, Efrima \& Zeiri [8] demonstrated that these drawbacks can 420 be overcome.

The low sensitivity of the tabletop RAMAN instrument itself could be another reason for

422 the weak signatures obtained in our study. In order to further discriminate the differences in the 423 spectral data, discriminant analysis was performed to show that the function was able to classify $424100 \%$ of $P$. aeruginosa cells and $85.9 \%$ of L. monocytogenes cells correctly. 


\subsection{Time Lapsed Image Analysis}

426

The 3D high throughput microfluidic platform was used in conjunction with optical

427 microscopy to image the morphology of L. monocytogenes treated with 37.2 and $200 \mu \mathrm{M}$

428 concentrations of IKAFKEATKVDKVVVLWTA peptide at $0,1,2$, and $3 \mathrm{~h}$. This experiment

429 was performed to visualize the effect of peptide on L. monocytogenes cells. Figure 6 shows the

430 time lapsed images of L. monocytogenes treated with 37.2 and $200 \mu \mathrm{M}$ peptide taken at $40 \mathrm{X}$

431 magnification over a period of $3 \mathrm{~h}$. Aggregation in the peptide-treated sample is significantly

432 lower than in the case of untreated cells The motility of the cells was restricted when comparing

4332 and $3 \mathrm{~h}$ treatments with $200 \mu \mathrm{M}$ of peptide used on L. monocytogenes. The effect of

434 antimicrobial soy peptide was observed to inhibit flocculation and reduce the motility of

435 bacterial cells. 

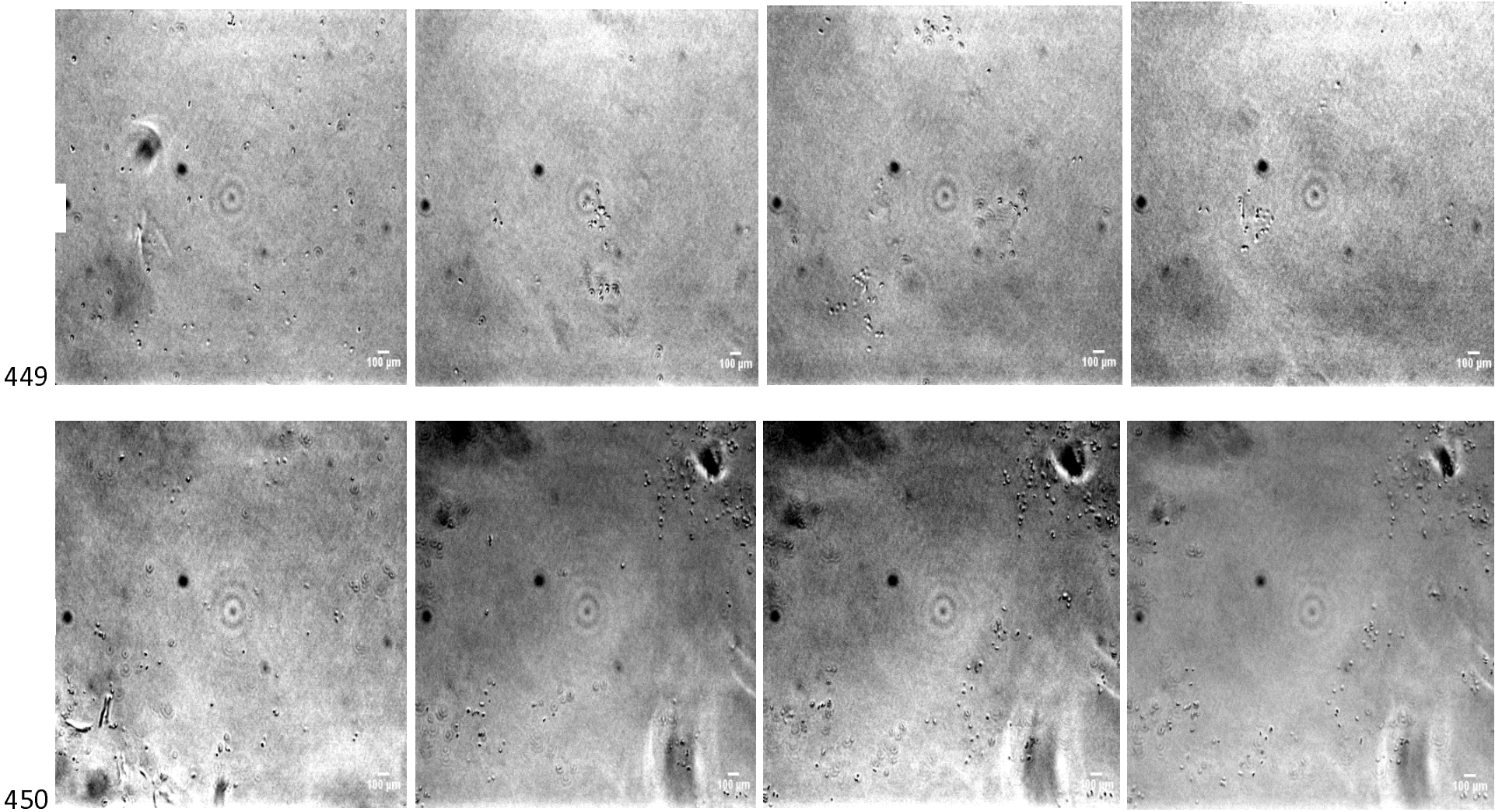

$451 \quad$ Figure 6. Time lapsed images of $L$. monocytogenes treated with $37.2 \mu \mathrm{M}$ and $200 \mu \mathrm{M}$ of long

452 chain soy peptide in the microfluidic device at $0,1,2$, and $3 \mathrm{~h}$ taken with the $40 \mathrm{x}$ lens of a Nikon

453 Eclipse Ti inverted microscope.

454

4. Conclusions

Antimicrobial peptides are a novel class of bio-pharmaceuticals that possess significant

457 therapeutic potential. The results of this study indicate that soy peptides PGTAVFK and

458 IKAFKEATKVDKVVVLWTA could possibly be used in the development of plant based,

459 biocompatible, and biodegradable alternative antimicrobial agents or antibiotics for use in the

460 food industry and medical field. 
There is a dire need to develop and exploit high throughput techniques for drug analysis andantimicrobial/antibiotic screening in the pharmaceutical industry. A high throughput, sensitive, and selective tool would drastically reduce the timelines for antimicrobial candidate

464 discovery and development within the pharmaceutical industry. Because of the ability to 465 integrate 3D microfluidic high-throughput drug screening platform with microscopy and 466 spectroscopy, rapid evaluation of antibiofilm candidates would help to prevent false positive 467 responses and will ultimately streamline preclinical trials.

\section{Acknowledgements}

471 Canada, Ontario Ministry of Research and Innovation, and the Ontario Ministry of Agriculture 472 and Food for funding this study.

\section{References}

475 [1] Ahadian, S., Ramon-Azcon, J., Estili, M., Obregon, R., Shiku, H., \& Matsue, T. (2014).

476 Facile and rapid generation of 3D chemical gradients within hydrogels for high- throughput drug

477 screening applications. Biosensors \& Bioelectronics, 59, 166-173.

478 [2] Bernatova, S., Samek, O., Pilat, Z., Sery, M., Jezek, J., Jakl, P., \& Ruzicka, F. (2013).

479 Following the mechanisms of bacteriostatic versus bactericidal action using RAMAN

480 spectroscopy. Molecules, 18(11), 13188-13199.

481 [3] Brand, G. D., Magalhaes, M., Tinoco, M., Aragao, F., Nicoli, J., Kelly, S. M., \& Bloch, C.

482 (2012). Probing protein sequences as sources for encrypted antimicrobial peptides. PLoS One, 483 7(9): e45848. 
484 [4] Correa, A., Daroit, D. J., Coelho, J., Meira, S., Lopes, F. C., Segalin, J., \& Brandelli, A.

485 (2011). Antioxidant, antihypertensive and antimicrobial properties of ovine milk caseinate

486 Hydrolyzed with a microbial protease. Journal of the Science of Food and Agriculture, 91(12),

$487 \quad 2247-2254$.

488 [5] Cozzone, A. J. (2012). An insight into future antibacterial therapy. Emerging Microbes and

489 Infections, $1, \mathrm{e} 38$.

490 [6] De Gelder, J., De Gussem, K., Vandenabeele, P., \& Moens, L. (2007). Reference database of

491 raman spectra of biological molecules. Journal of Raman Spectroscopy, 38(9), 1133-1147.

492 [7] DiCicco, M., \& Neethirajan, S. (2014). An in vitro microfluidic gradient generator platform

493 for antimicrobial testing. BioChip Journal, 8(4), 282-288.

494

495

496

497

498

499

500

501

502

503

504

505

506

507

[8] Efrima, S., \& Zeiri, L. (2009). Understanding SERS of bacteria. Journal of Raman Spectroscopy, 40(3), 277-288.

[9] Faley, S. L., Copland, M., Wlodkowic, D., Kolch, W., Seale, K. T., Wikswo, J. P., \& Cooper, J. M. (2009). Microfluidic single cell arrays to interrogate signalling dynamics of individual, patient-derived hematopoietic stem cells. Lab on a Chip, 9(18), 2659-2664.

[10] FitzGerald, R. J., Murray, B. A., \& Walsh, D. J. (2004). Hypotensive peptides from milk proteins. Journal of Nutrition, 134(4), 980S-988S.

[11] Fitzgerald, R. J., \& Murray, B. A. (2006). Bioactive peptides and lactic fermentations. International Journal of Dairy Technology, 59(2), 118-125.

[12] Fjell, C. D., Hiss, J. A., Robert, E. W. H., \& Schneider, G. (2011). Designing antimicrobial peptides: Form follows function. Nature Reviews Drug Discovery, 11(1), 37-51.

[13] Gandhi, M., \& Chikindas, M. L. (2007). Listeria: A foodborne pathogen that knows how to survive. International Journal of Food Microbiology, 113(1), 1-15. 
508

509

510

511

512

513

514

515

516

517

518

519

520

521

522

523

524

525

526

527 [21] Kumar, A., Karig, D., Acharya, R., Neethirajan, S., Mukherjee, P. P., Retterer, S., \&

528

529

530

[14] Genemed Synthesis Inc. (2014). Retrieved February 26, 2015 from

http://www.genemedsyn.com/.

[15] Guzelian, A. A., Sylvia, J. M., Janni, J. A., Clauson, S. L., \& Spencer, K. M. (2002). SERS

of whole-cell bacteria and trace levels of biological molecules. Proceedings of SPIE4577,

Vibrational Spectroscopy-based Sensor Systems, 182 (February 13, 2002).

[16] He, J., Mu, X., Guo, Z., Hao, H., Zhang, C., Zhao, Z., \& Wang, Q. (2014). A novel microbead-based microfluidic device for rapid bacterial identification and antibiotic susceptibility testing. European Journal of Clinical Microbiology \& Infectious Diseases, 33(12), 2223-2230.

[17] Ju, S. L., \& Greenberg, M. L. (2004). 1D- myo- inositol 3- phosphate synthase:

Conservation, regulation, and putative target of mood stabilizers. Clinical Neuroscience Research, 4(3-4), 181-187.

[18] Kim, J., Park, H., \& Chung, S. (2012). Microfluidic approaches to bacterial biofilm formation. Molecules, 17, 9818-9834.

[19] Kitts, D. D., \& Weiler, K. (2003). Bioactive proteins and peptides from food sources. applications of bioprocesses used in isolation and recovery. Current Pharmaceutical Design, 9(16), 1309-1323.

[20] Korhonen, H., \& Pihlanto, A. (2003). Food-derived bioactive peptides- opportunities for designing future foods. Current Pharmaceutical Design, 9(16), 1297-1308. Doktycz, M. J. (2013). Microscale confinement features can affect biofilm formation.

Microfluidics and Nanofluidics, 14(5), 895-902.

[22] Li, B., Qiu, Y., Glidle, A., McIlvenna, D., Luo, Q., Cooper, J., \& Yin, H. B. (2014). 
531 Gradient microfluidics enables rapid bacterial growth inhibition testing. Analytical Chemistry,

532

533

534

535

536

537

538

539

540

541

542328.

543 [26] Mangoni, M. L., \& Shai, Y. (2011). Short native antimicrobial peptides and engineered

544 ultrashort lipopeptides: Similarities and differences in cell specificities and modes of action.

545 Cellular and Molecular Life Sciences, 68(13), 2267-2280.

546 [27] Maróti, G., Kereszt, A., Kondorosi, É, \& Mergaert, P. (2011). Natural roles of antimicrobial

547 peptides in microbes, plants and animals. Research in Microbiology, 162(4), 363-374.

548 [28] McClean, S., Beggs, L. B., \& Welch, R. W. (2014). Antimicrobial activity of

549 antihypertensive food- derived peptides and selected alanine analogues. Food Chemistry, 146,

$550 \quad 443-447$.

551 [29] Moller, N. P., Scholz-Ahrens, K., Roos, N., \& Schrezenmeir, J. (2008). Bioactive peptides

552 and proteins from foods: Indication for health effects. European Journal of Nutrition, 47(4), 171-

553182. 
554 [30] Motyl, M., Dorso, K., Barrett, J., \& Giacobbe, R. (2006). Basic microbiological techniques

555

556

557

558

559

560

561

562

563

564

565

566

567

568

569

570

571

572

573

574

575

576

used in antibacterial drug discovery. Current Protocols in Pharmacology, Chapter 13:

Unit13A.3.

[31] Münchberg, U., Rösch, P., Bauer, M., \& Popp, J. (2014). Raman spectroscopic identification of single bacterial cells under antibiotic influence. Analytical and Bioanalytical Chemistry, 406(13), 3041-3050.

[32] Ripolles, D., Harouna, S., Parrón, J. A., Calvo, M., Pérez, M. D., Carramiñana, J. J., \& Sánchez, L. (2015). Antibacterial activity of bovine milk lactoferrin and its hydrolysates prepared with pepsin, chymosin and microbial rennet against foodborne pathogen Listeria monocytogenes. International Dairy Journal, 45, 15-22.

[33] Sackmann, E. K., Fulton, A. L., \& Beebe, D. J. (2014). The present and future role of microfluidics in biomedical research. Nature, 507, 181-189.

[34] Sánchez-Gómez, S., Ferrer-Espada, R., Stewart, P. S., Pitts, B., Lohner, K., \& de Tejada, G. M. (2015). Antimicrobial activity of synthetic cationic peptides and lipopeptides derived from human lactoferricin against Pseudomonas aeruginosa planktonic cultures and biofilms. BMC microbiology, 15(1), 137.

[35] Sánchez-Vásquez, L., Silva-Sanchez, J., Jiménez-Vargas, J. M., Rodríguez-Romero, A., Muñoz-Garay, C., Rodríguez, M. C., Gurrola, G. B., \& Possani, L. D. (2013). Enhanced antimicrobial activity of novel synthetic peptides derived from vejovine and hadrurin.

Biochimica Et Biophysica Acta-General Subjects, 1830, 3427-3436.

[36] Sharma, S., Singh, R., \& Rana, S. (2011). Bioactive peptides: A review. International Journal Bioautomation, 15(4), 223-250.

[37] Shoemaker, R. H., Scudiero, D. A., Melillo, G., Currens, M. J., Monks, A. P., Rabow, A. A., 
577 Covell, D. G., \& Sausville, E. A. (2002). Application of high-throughput, molecular-targeted

578

579

580

581

582

583

584

585

586

587

588

589

590

591

592

593

594

595

596

597

598

599 screening to anticancer drug discovery. Current Topics in Medicinal Chemistry, 2(3), 229-246.

[38] Sockalingum, G. D., Lamfarraj, H., Beljebbar, A., Pina, P., Delavenne, M., Witthuhn, F.,

Allouch, P., \& Manfait, M. (1999). Vibrational spectroscopy as a probe to rapidly detect, identify, and characterize micro-organisms. Proceedings of SPIE 3608, Biomedical Applications of Raman Spectroscopy, 185 (April 9, 1999).

[39] Veillon, L., Bourgeois, J., Leblanc, A., Henderson, G., Marx, B. D., Muniruzzaman, S., \& Laine, R. (2014). Myo- inositol and phytate are toxic to formosan subterranean termites (isoptera: Rhinotermitidae). Journal of Economic Entomology, 107(5), 1800-1812.

[40] Vogel, H. J., Schibli, D. J., Jing, W. G., Lohmeier-Vogel, E., Epand, R. F., \& Epand, R. M. (2002). Towards a structure- function analysis of bovine lactoferricin and related tryptophan- and arginine- containing peptides. Biochemistry and Cell Biology, 80(1), 49-63.

[41] Wang, S. Y., \& Gunsch, C. K. (2011). Effects of selected pharmaceutically active compounds on treatment performance in sequencing batch reactors mimicking wastewater treatment plants operations. Water Research, 45(11), 3398-3406.

[42] Weibel, D. B., Diluzio, W. R., \& Whitesides, G. M. (2007). Microfabrication meets microbiology. Nature Reviews Microbiology, 5(3), 209-218.

[43] White, D. G., Zhao, S. H., Simjee, S., Wagner, D. D., \& McDermott, P. F. (2002). Antimicrobial resistance of foodborne pathogens. Microbes and Infection, 4(4), 405-412. [44] Whitesides, G. M., Ostuni, E., Takayama, S., Jiang, X., \& Ingber, D. E. (2001). Soft lithography in biology and biochemistry. Annual Review of Biomedical Engineering, 3, 335-373.

[45] Wlodkowic, D., Faley, S., Zagnoni, M., Wikswo, J. P., \& Cooper, J. M. (2009).

Microfluidic single-cell array cytometry for the analysis of tumor apoptosis. Analytical 
600

601

602

603

604

605

606

607

608

609

610

611

612

613

614

615

616

617

Chemistry, 81(13), 5517-5523.

[46] Wolcott, R., Costerton, J., Raoult, D., \& Cutler, S. (2013). The polymicrobial nature of biofilm interaction. Clinical Microbiology of Infection, 19(2), 107-112.

[47] World Health Organization. (2014). WHO’s first global report on antibiotic resistancel reveals serious, worldwide threat to public health. Retrieved November 21, 2014, from http://www.who.int/mediacentre/news/releases/2014/amr-report/en/ [48] Wright, E., Neethirajan, S., Warriner, K., Retterer, S. T., \& Srijanto, B. R. (2014). Single cell swimming dynamics of listeria monocytogenes using a nanoporous microfluidic platform. Lab on a Chip, 14(5), 938-946.

[49] Wu, Q., Gao, D., Wei, J., Jin, F., Xie, W., Jiang, Y., \& Liu, H. (2014). Development of a novel multi- layer microfluidic device towards characterization of drug metabolism and cytotoxicity for drug screening. Chemical Communications, 50(21), 2762-2764. 